\title{
L. Keller, Lire, traduire, éditer Proust
}

\section{Mariolina Bertini}

\section{(2) OpenEdition}

\section{Journals}

\section{Edizione digitale}

URL: http://journals.openedition.org/studifrancesi/10037

DOI: 10.4000/studifrancesi. 10037

ISSN: 2427-5856

\section{Editore}

Rosenberg \& Sellier

\section{Edizione cartacea}

Data di pubblicazione: 1 août 2017

Paginazione: 393

ISSN: 0039-2944

\section{Notizia bibliografica digitale}

Mariolina Bertini, «L. Keller, Lire, traduire, éditer Proust», Studi Francesi [Online], 182 (LXI | II) | 2017, online dal 01 août 2017, consultato il 10 janvier 2021. URL: http://journals.openedition.org/studifrancesi/ 10037 ; DOI: https://doi.org/10.4000/studifrancesi.10037

Questo documento è stato generato automaticamente il 10 janvier 2021.

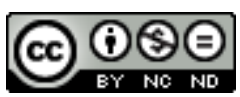

Studi Francesi è distribuita con Licenza Creative Commons Attribuzione - Non commerciale - Non opere derivate 4.0 Internazionale. 


\title{
L. Keller, Lire, traduire, éditer Proust
}

\author{
Mariolina Bertini
}

\section{NOTIZIA}

LUZIUS KELLER, Lire, traduire, éditer Proust, Paris, Classiques Garnier, 2016, 317 pp.

1 Questo volume raccoglie una serie di contributi nati in margine a una grande impresa editoriale: l'edizione tedesca delle opere complete di Proust, nota come Frankfurter Ausgabe, che l'autore ha diretto e annotato dal 1988 al 2002. La Frankfurter Ausgabe è stata un laboratorio d'eccezione e un crocevia internazionale degli studi proustiani: se l'annotazione di Keller alla Recherche ha tenuto conto delle edizioni francesi e italiane, la fortunata edizione spagnola del Contre Sainte-Beuve, a cura di Silvia Acierno e di Julio Baquero Cruz, ha adottato come testo di riferimento il Contro Sainte-Beuve tedesco, più rigoroso dell'edizione Fallois ma anche molto più ampio dell'edizione Clarac del 1971.

2 La prima sezione del volume, "Éditer Proust», affronta i problemi cui si trova confrontato chi lavori a un'edizione della Recherche. Limitarsi a un commento documentario o arrischiare proposte interpretative? La risposta di Keller, conforme all'impostazione del suo commento nella Frankfurter Ausgabe, è che il discorso documentario - in cui vengono identificate le citazioni letterarie o pittoriche e le allusioni a eventi politici e a personaggi storici - trova il suo necessario prolungamento in una riflessione critica puntuale, che lo utilizzi per l'interpretazione del testo. Un altro problema è quello posto dal carattere postumo e incompiuto degli ultimi volumi della Recherche: chi volesse rispettare alla lettera le ultime disposizioni di Proust, dovrebbe adottare la versione "breve" di Albertine disparue, conforme all'ultimo dattiloscritto approvato dall'autore, sacrificando parti bellissime presenti soltanto nel manoscritto. Keller approva la soluzione del problema adottata nella sua edizione da Nathalie Mauriac Dyer: offrire la versione breve, poi chiedere al lettore di tornare indietro nella diegesi e di leggere la versione più estesa del manoscritto. Tre manoscritti ritrovati, che Keller riproduce, rendono infine questa sezione imperdibile 
per tutti i proustiani: due pastiches inediti dei Goncourt e una lettera a Reynaldo Hahn di argomento musicale e letterario.

3 La seconda sezione, «Traduire Proust», non verte soltanto su problemi della traduzione in lingua tedesca, ma anche su quel traduttore d'eccezione di Proust che fu Giacomo Debenedetti. Quanto alla terza e alla quarta sezione, «Lire Proust. Du siècle des Lumières à la Belle époque» e "Lire Proust. La "collection Marcel Proust"», sono per la maggior parte dedicate a un campo di cui Keller è tra i massimi esperti: quello del rapporto di Proust con la pittura. È un rapporto che non resta affatto eguale a sé stesso nel tempo. Nel giovanile Jean Santeuil, per esempio, la descrizione di alcuni quadri di Monet (che Keller è stato il primo ad identificare) è per Proust l'occasione di cimentarsi in una prosa poetica che risente del clima simbolista. Ma già la descrizione di un Corot immaginario si orienta, ancora in Jean Santeuil, in un'altra direzione e annuncia quell'integrazione dell'ekphrasis nella narrazione che sarà, come ci spiega l'autore, peculiare della Recherche. Seguendo l'evoluzione del gusto di Proust dall'impressionismo al cubismo, attraverso esempi sempre pertinenti, Keller ci guida in queste sezioni in una visita della «Collection Marcel Proust» estremamente innovativa. Accanto alle opere su cui la critica ha lungamente dibattuto, individua una ricca serie di "quadri nascosti" che collegano a suggestioni pittoriche scene del romanzo nelle quali non si parla esplicitamente di pittura. E fornisce l'interpretazione più convincente alla riflessione di Bergotte che, davanti all'opera di Vermeer, si dice che avrebbe dovuto «passer plusieurs couches de couleur» sulla sua prosa: è un'allusione ai diversi strati di significato del testo proustiano, in cui una ricca palette verbale mette i suoi colori al servizio della complessità tematica. 